\title{
Spatial-Temporal Variations and Socio-Economic Influencing Factors of Air Quality in China's Major Cities During COVID-19
}

\section{Xinlin Yan ( $\square$ yanxinlin2010@163.com )}

Nanjing University of Aeronautics and Astronautics https://orcid.org/0000-0002-9821-7093

Tao Sun

Nanjing University of Aeronautics and Astronautics https://orcid.org/0000-0003-3121-2340

\section{Research Article}

Keywords: COVID-19, Lockdown, Regional air quality, China, Spatial aggregation, Socio-economic factors, Regional policy

Posted Date: December 30th, 2021

DOl: https://doi.org/10.21203/rs.3.rs-1136475/v1

License: (c) (i) This work is licensed under a Creative Commons Attribution 4.0 International License.

Read Full License 


\section{Spatial-temporal Variations and Socio-economic Influencing Factors of Air} Quality in China's Major Cities During COVID-19

\section{Xinlin Yan ${ }^{1}$,Tao Sun ${ }^{2}$}

${ }^{12}$ College of Economics and Management, Nanjing University of Aeronautics and Astronautics, Nanjing Jiangsu 211106, China

Abstract: Due to the emergence of COVID-19 in Wuhan in January 2020, the central government of China announced that Wuhan was in "lockdown," the activities of the country's citizens were restricted. This study selected three standard air quality indexes AQI, PM2.5, and PM10 of 2017-2021 in 40 major cities of seven regions in China to analyze their changes, spatial-temporal distributions, and socio-economic influencing factors. Compared with 2019, AQI, PM2.5, and PM10 decreased by 22.54\%, 13.94\%, and 22.30\%, respectively, and the days with AQI level "AQI $\leq 100$ " increased from $89 \%$ to $100 \%$ during the "lockdown" in 2020. Due to different degrees of industrialization, the decline range of Northeast, Yangtze River Delta, and Pearl River Delta areas is more than that of the Southwest, BTH, Northwest, and Central areas, the concentration of air pollutants shows significant regional characteristics. The AQI before and after the "lockdown" in 2020 showed significant spatial autocorrelation, and the cities' AQI in the north present high aggregation, and the cities in the south are in low aggregation. From the data at the national level, the changes of the four socio-economic factors of roadway passenger volume (RPV), construction area (CA), coal-fired power (CP), and the proportion of industrial added value in GDP (IND) significantly influenced AQI. This study gives regulators confidence that if the government implements regionalized air quality improvement policies according to the characteristics of each region in China and reasonably plans socio-economic activities, it is expected to improve China's air quality sustainably.

Keywords: COVID-19, Lockdown, Regional air quality, China, Spatial aggregation, Socio-economic factors, Regional policy

Authors: Xinlin Yan (1993-), Men, Zhengzhou native of Henan Province, PHD candidate, College of Economics and Management, Nanjing University of Aeronautics and Astronautics

Tao Sun (1959-), Men, Taian native of Shandong Province, professor and doctoral supervisor of College of Economics and Management, Nanjing University of Aeronautics and Astronautics Corresponding Author: Tao Sun; Email: nuaastao@163.com; Telephone: +86-13951941170 Address: College of Economics and Management, Nanjing University of Aeronautics and Astronautics, No. 29, Jiangjun Avenue, Nanjing 211106, Jiangsu, China 


\section{Introduction}

In December 2019, the first case of unknown pneumonia in China appeared in Wuhan, and then the virus causing pneumonia spread rapidly in China and even around the world and was named COVID-19 by WHO (WHO, 2021). Due to the spread of covid-19 from Wuhan to other provinces in China, the Chinese government announced the "lockdown" of Wuhan on January 23, 2020. Subsequently, 31 provinces' governments announced the launch of the first-class response to major national public health events and began implementing epidemic restriction measures nationwide. These government restrictions include residents being restricted from going out, large gatherings being banned, schools, shopping centers, construction sites, and factories being temporarily suspended, and traffic and transportation being controlled. Since the "lockdown" started during the Chinese new year, traffic control restricted a large number of population movements, which affected the economic activities of the whole country, but also provided an opportunity for China's air pollution research.

Studies have shown that air quality will change during significant events. During the 2008 Olympic Games and the 2014 APEC summit, Beijing issued policies to restrict factory production and transportation in order to improve air quality (Chen, Jin, Kumar and Shi, 2013). During the annual plenary session of the National People's Congress and the National Committee of the Chinese People's Political Consultative Conference from 2013 to 2016, due to the temporary implementation of strict air quality management measures at the annual meeting, the air index AQI decreased by 5.7\%. During the APEC meeting in 2014, AQI index decreased by $35.9 \%$ due to the most stringent air control measures issued by the central government, and the values of $\mathrm{PM}_{2.5}, \mathrm{PM}_{10}, \mathrm{SO}_{2}, \mathrm{NO}_{2}$, and CO decreased by 41.3\%, 48.2\%, 56.5\%, 38.9\% and 35.5\% respectively (B.Li et al., 2017). The 2016 G20 Summit in Hangzhou proved that the holding of large-scale events is related to the transformation of air quality ( $\mathrm{Li}$ et al., 2019). However, the impact of the COVID-19 "lockdown" is unmatched by the previous major events.

Recent studies in many countries had shown that the blockade caused by the spread of covid-19 and the reduction of traffic and industrial activities have a positive impact on the environment ( $\mathrm{Li}$ et al., 2020). The study found that the AQI, $\mathrm{PM}_{2.5}$, and $\mathrm{PM}_{10}$ of major cities in India decreased 
significantly during the one month of blockade (Naqvi, mutreja, Shakeel and Siddiqui, 2021; Das et al., 2021; Yadav et al., 2020). By measuring aerosol composition during covid-19, it was found that anthropogenic emissions reduce the process of promoting the formation of secondary aerosols (Sun et al., 2020). The study found that the emission level of $\mathrm{PM}_{2.5}$ was closely related to the death of covid-19 infected people, and the areas dominated by fossil fuel emissions significantly affected the number of covid-19 cases (Sahu et al., 2021; Ali et al., 2021).

Based on the conventional pollutant monitoring data of four years and three months in the same period from 2017 to 2021, this paper analyzes air quality indexes in 40 major cities in China before, during, and after the "lockdown". On this basis, the spatial measurement and social factor driving force models are established to study the differences of socio-economic factors on air quality both national and regional wide. The research results are helpful to understand the evidence of the impact of human social activities on air quality during the period of strict policy restrictions, as well as the regional characteristics of air pollution, and provide a reference for formulating related air pollution control policies and measures.

\section{Materials and methods}

\subsection{Data sources and processing}

This paper selects the monitoring point data of 40 major cities in China, which spatially covers the developed cities in all provinces and regions in China. We collected daily air pollution data from China's national environmental monitoring center from December to March 2017 and selected conventional air quality indexes $\mathrm{AQI}, \mathrm{PM}_{2.5}$, and $\mathrm{PM}_{10}$.

Due to the characteristics of regional transmission of air pollution, the air pollutants concentration of each city will be affected by the surrounding cities (X. Li et al., 2017). In this study, 40 major cities are divided into seven regions according to their economic development level, industrial and energy structure, urban agglomeration development characteristics, regional climate characteristics, and geographical location (Miao et al., 2019; Xu et al., 2021; Hao et al., 2018; Luo et al., 2021; Zhu et al, 2018; Wei et al., 2020; Li et al., 2021), details are shown in Table 1. 


\begin{tabular}{|c|c|}
\hline Areas & Cities \\
\hline Northeast & Harbin, Hohhot, Jilin, Changchun, Shenyang, Dalian \\
\hline Beijing-Tianjin- & Beijing, Tianjin, Shijiazhuang, Tangshan, Jinan, Yantai, Qingdao \\
\hline Hebei $($ BTH) & \\
\hline Yangtze River & Shanghai, Nanjing, Suzhou, Wuxi, Hefei, Hangzhou, Ningbo \\
\hline Delta & \\
\hline Pearl River Delta & Guangzhou, Shenzhen, Fuzhou, Quanzhou, Nanchang \\
\hline Southwest & Chongqing, Chengdu, Guiyang, Kunming, Nanning \\
\hline Central & $\begin{array}{l}\text { Zhengzhou, Luoyang, Nanyang, Wuhan, Xiangyang, Changsha, } \\
\text { Taiyuan, Xian }\end{array}$ \\
\hline Northwest & Lanzhou, Yinchuan \\
\hline
\end{tabular}

Since January 23, 2020, the 29th of the lunar calendar, is the day before the Chinese New Year's Eve, which is during the Chinese Spring Festival holiday, people all over the country are reuniting with their families. Even if there is no "lockdown," the economic activities in all regions of China will be significantly reduced. In order to make the data analysis more accurate, We selected years 2018, 2019, 2021 as the lunar calendar date range of the same period of the "lockdown" in 2020 for analysis, that is, 18 days before the 29th of the lunar calendar (before the "lockdown"), 18 days after the 29th of the lunar calendar (during the "lockdown"), and 18 days after the end of the "lockdown."

\subsection{Spatial effect test model of air quality}

The global Moran I can explain whether the air quality per unit city has aggregation in space, judge the similarity between units in adjacent cities, and describe the overall distribution of air quality per unit city (Moran 1950). The calculation formula is as follows:

$$
\text { Moran's I }=\frac{\sum_{\mathrm{i}=1}^{\mathrm{n}} \sum_{\mathrm{j}=\mathrm{i}}^{\mathrm{n}} \mathrm{W}_{\mathrm{ij}}\left(\mathrm{X}_{\mathrm{i}}-\overline{\mathrm{x}}\right)-\left(\mathrm{x}_{\mathrm{j}}-\overline{\mathrm{x}}\right)}{\mathrm{S}^{2} \sum_{\mathrm{i}=1}^{\mathrm{n}} \sum_{\mathrm{j}=\mathrm{i}}^{\mathrm{n}} \mathrm{W}_{\mathrm{ij}}}
$$

$X_{i}$ and $X_{j}$ will be the air pollution levels of city $i$ and $j$; $n$ is the total number of cities, $\bar{x}$ is the average air pollution levels of 40 cities; $W_{i j}$ is the spatial weight matrix, set to 1 if area $i$ is adjacent to area $\mathrm{j}$; otherwise, it is 0 .

The global Moran I was proposed by Anselin in 1995 and can be used to explain the correlation between the air quality of a unit area and its surrounding area (Anselin 1995). The calculation formula is as follows:

$$
\text { Local Moran's } I=\frac{\left(\mathrm{X}_{\mathrm{i}}-\overline{\mathrm{x}}\right) \sum_{\mathrm{j}=1}^{\mathrm{n}} \mathrm{W}_{\mathrm{ij}}\left(\mathrm{X}_{\mathrm{j}}-\overline{\mathrm{x}}\right)}{\mathrm{S}^{2}}
$$


$X_{i}$ and $X_{j}$ will be the air pollution levels of city $i$ and $j ; n$ is the total number of cities, $\mathrm{W}_{\mathrm{ij}}$ is the spatial weight matrix, $\mathrm{m}$ is the number of cities that around city $\mathrm{i}$.

The value range of the two models is $[-1,1]$, and the I value can judge the aggregation degree of urban air quality level. I > 0 indicates that there is a positive spatial correlation, and the urban correlation, and the urban air quality index presents a uniform or dispersed distribution of highlow or low-high; $\mathrm{I}=0$ indicates that the urban air quality index is randomly distributed and there is no autocorrelation. In this paper, the spatial autocorrelation and aggregation of air quality observations AQI among 40 major cities in China will be presented through the scatter diagram, in which the first and third quadrants of the scatter diagram represent the positive spatial correlation of observations and the second and fourth quadrants represent the negative spatial correlation.

\subsection{Air quality driving force model}

Due to the "lockdown" policy, traffic is controlled, factories and construction sites are shut down, shopping malls and residential communities are closed, and unnecessary economic activities are suspended. This paper selects RPV, CA, CP, and IND as four explanatory variables, and AQI is the explained variable. The socio-economic data are from the China Urban Statistical Yearbook, the National Bureau of Statistics, and the China Automobile Industry Association. The analysis model is as follows:

$$
Y_{t}=\beta_{0}+\beta_{1} R P V_{t}+\beta_{2} C A_{t}+\beta_{3} C P_{t}+\beta_{4} I N D_{t}+\varepsilon
$$

$\mathrm{Y}$ represents dependent variable AQI. PVS, REA, CP, IND are independent variables, $t$ represents time, $\beta\left[\beta_{o}, \beta_{1}, \beta_{2}, \ldots, \beta_{4}\right]$ are model parameters to be estimated; $\varepsilon$ represents linear random error.

\section{Results and Discussion}

\subsection{Results}

Figure 1 shows the daily value changes of $\mathrm{AQI}, \mathrm{PM}_{2.5}$, and $\mathrm{PM}_{10}$ in China and its seven regions during the 54 days from December 29 to February 4 in the same period of the lunar calendar 
from 2017 to 2021. Phase I, II, and III are 18 days before the "lockdown," 18 days in the "lockdown," and 18 days after the "lockdown" in 2020. From a national perspective, in phase II in 2020, compared with phase I, AQI, $\mathrm{PM}_{2.5}$ and $\mathrm{PM}_{10}$ decreased by $15.83 \%, 16.08 \%$, and $22.12 \%$ respectively. It can be seen that the impact of Wuhan City's "lockdown" policies and measures is national wide, and other provinces have certain responses to the policies. In phase III, the three indexes showed an upward trend, which may be affected by the resumption of factories and the restoration of traffic control (Li et al., 2020). Compared with the same period in 2019, the three indexes in phase II and III in 2020 decreased, AQI, $\mathrm{PM}_{2.5}$ and $\mathrm{PM}_{10}$ decreased by $22.54 \%, 13.94 \%$, and $22.30 \%$ respectively, and the three indexes decreased by $4.22 \%, 16.26 \%$, and $4.72 \%$ respectively compared with the same period in 2018. It can be seen that the implementation of the city closure policy in 2020 has a positive impact on the concentration of three indexes, both month on month and year on year.

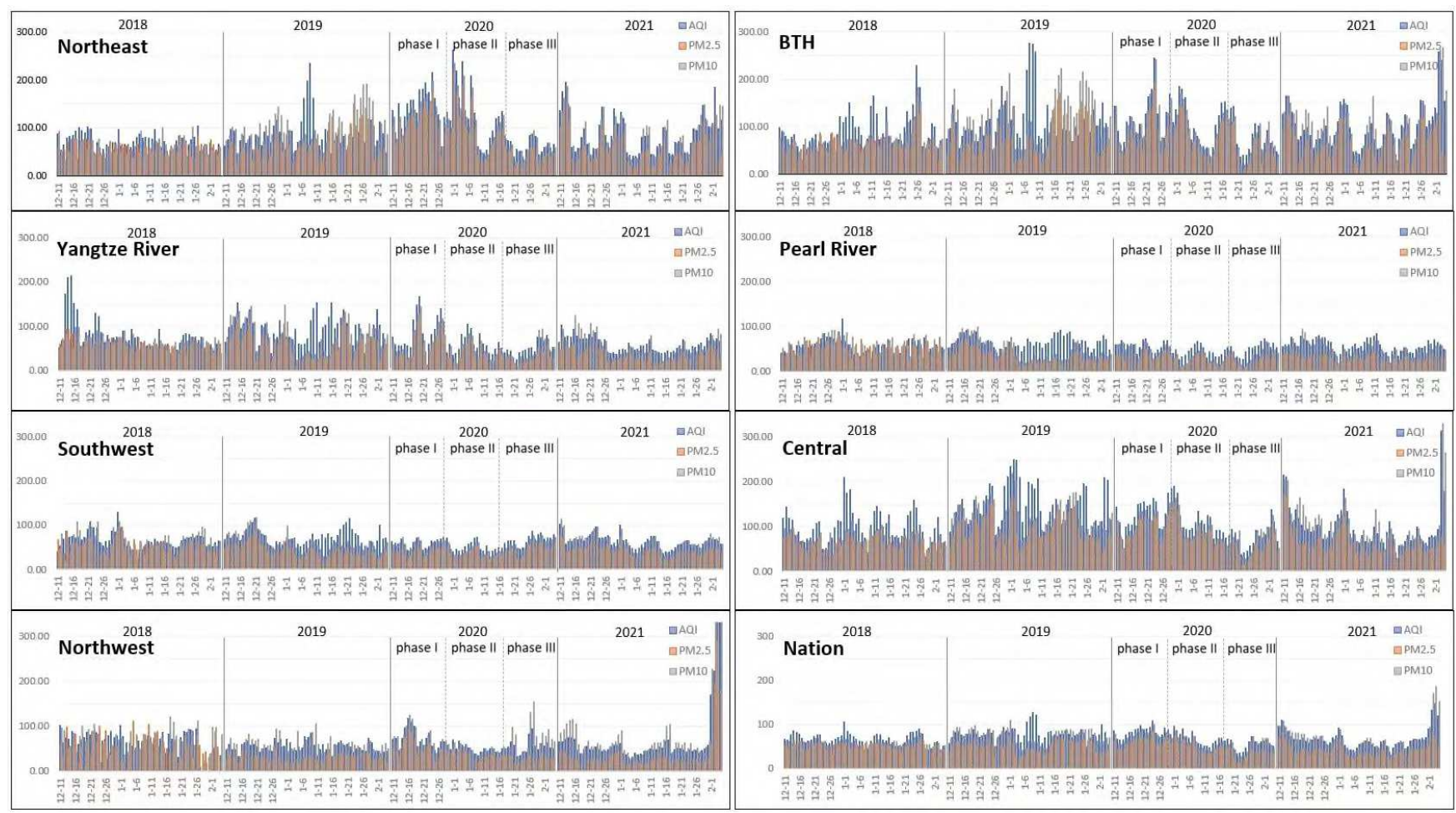

Figure 1 Fluctuations of AQI, PM2.5, PM10 values in seven regions and national wide during the "lockdown" from 2018 to 2021 From the regional perspective, in 2020, AQI, $\mathrm{PM}_{2.5}$, and $\mathrm{PM}_{10}$ in Northeast, Yangtze River Delta, and Pearl River Delta showed a significant downward trend in phases II to III compared with phase I, reaching more than $30 \%$. It can be seen that the "lockdown" has an obvious effect 
on human activities. Due to the intensive China's heavy industry in Northeast China, the "lockdown" stopped most production and processing factories, resulting in reduced air pollutant emissions. The Yangtze River Delta and the Pearl River Delta are located in China's coastal areas and belong to the two regions with the most developed economy in China. The secondary industry is developed, and the trade import and export business is busy. Under the "lockdown" and trade control policies, the large-scale shutdown of factories leads to the reduction of air pollutant emissions, which may lead to the decline of air quality indexes (Fujii, Managi and Kaneko, 2013).

The AQI, $\mathrm{PM}_{2.5}$, and $\mathrm{PM}_{10}$ of four regions of Southwest, BTH, Northwest, and Central showed a more stable change trend in 2020 compared with the three regions of Northeast, Yangtze River Delta, and Pearl River Delta. Compared with Northeast, Yangtze River, and Pearl River Delta, the development of secondary industry in Southwest, Northwest, and Central lags behind, and the "lockdown" measures have relatively little impact on the air pollution emission of factories. The secondary industry in the BTH area is developed, and the air quality indexes does not fluctuate significantly after the "lockdown" began. It might be that the BTH area is located in Bohai Bay, with a strong sea breeze. The change of air pollutant concentration level is affected by natural factors such as wind speed and wind direction or the diffusion of air pollution in other cities and counties (Shi et al., 2019).

\subsection{Days to reach various levels of air quality}

Figure 2 shows the proportion of 54 days of AQI air quality levels in China and seven regions during the "lockdown" in 2020 and the same period in 2019. The outer ring of the ring chart is the data in 2020 and the inner ring is the data in 2019. According to Chinese Environmental Quality Index (AQI) Technical Regulation "HJ633-2012," AQI air quality index is divided into six levels: Excellent $(0<A Q I \leq 50)$, Good $(50<A Q I \leq 100)$, Light pollution $(100<$ $A Q I \leq 150)$, Moderate pollution $(150<A Q I \leq 200)$, Heavy pollution $(200<A Q I \leq 300)$, Serious pollution $(300>A Q I)$. 


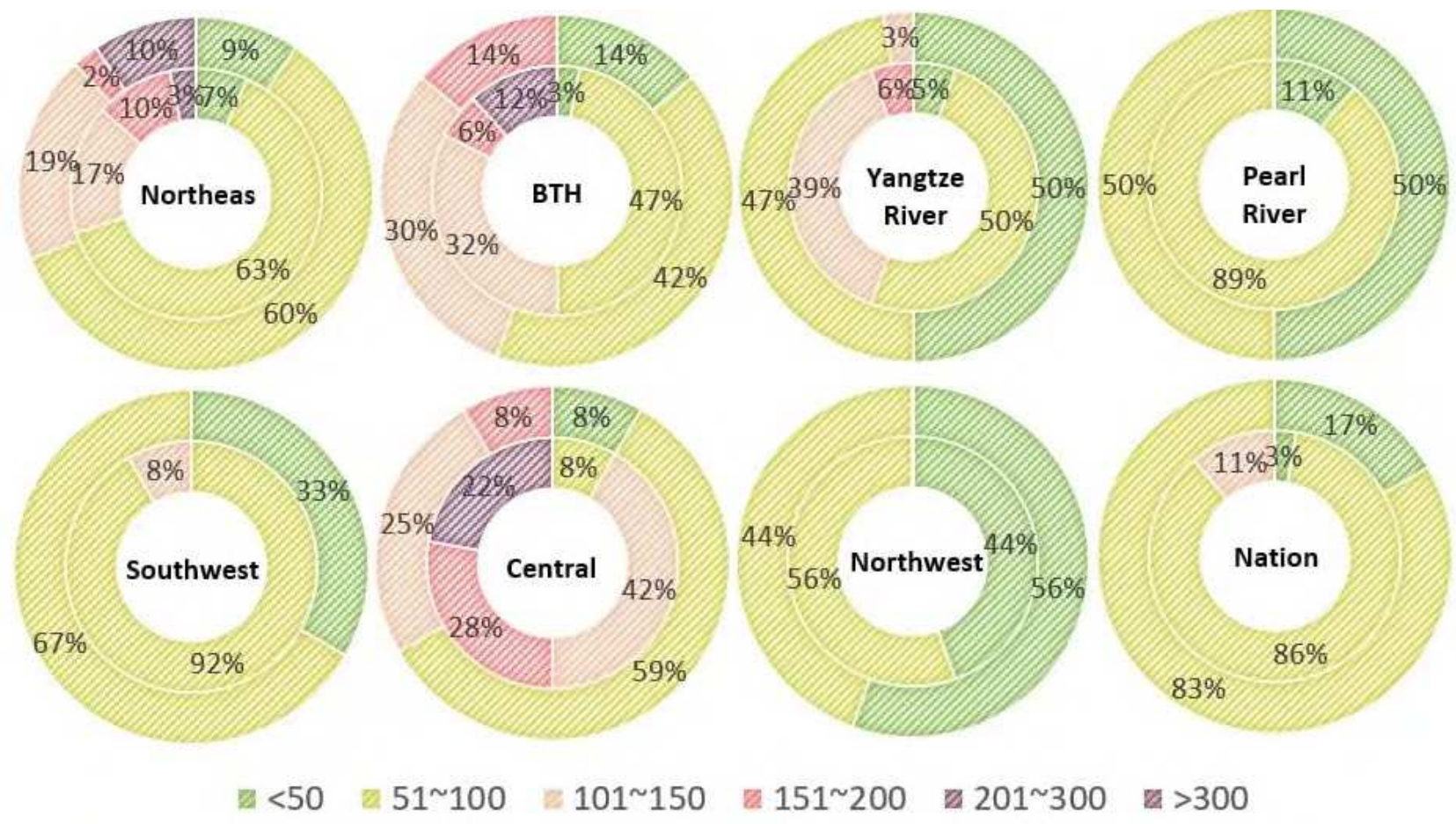

Figure 2 The proportions of days that reach six levels of AQI during "lockdown" in 2019-2020

From nationwide, in the same "lockdown" period of 2019, the average number of days with Good air quality or above accounted for $89 \%$, the number of days with light pollution accounted for $11 \%$, and the number of days with Good air quality or above accounted for $100 \%$ during the "lockdown" in 2020. During the "lockdown" in 2020, the proportion of the average number of days reaching Good or above level in 40 major cities in China increased compared with 2019.

During the "lockdown" of seven regions in China in 2020, the proportion of days with Light pollution and below decreased compared with the same period in 2019, which can be observed from Figure 2 that the proportion of pollution days in 2019 is ranked from high to low as central (92\%), BTH (50\%), Yangtze River Delta (46\%), Northeast (20\%), Southwest (8\%) and Northwest (0\%), Pearl River Delta (0\%), from high to low in 2020, followed by BTH (44\%), central (33\%), Northeast (31\%), Yangtze River Delta (3\%), Southwest (0\%), Northwest (0\%), Pearl River Delta (0\%). In 2019 and 2020, the Central area and BTH area are the two most polluted regions, and the number of pollution days is much higher than the national average. Southwest, Northwest, and Pearl River Delta are the three least polluted regions in both years, while Northeast area is the only region with an increase in pollution days in 2020. 


\subsection{AQI spatial distribution}

Figure 3 shows the comparison chart of the global spatial autocorrelation analysis results of AQI concentrations in 40 major cities in China 18 days before and after the "lockdown" in 2020. The Moran index results before and after the "lockdown" are 0.669 and 0.656 respectively, which are both greater than 0 , and significant at the level of $1 \%$, indicating that the air quality in major cities in China shows significant spatial autocorrelation, and the air pollution has regional aggregation. In the comparison chart, most cities before and after the "lockdown" are located in the first and third quadrants. Before the "lockdown," only two cities are located in the second quadrant. After the "lockdown," three cities are in the second quadrant, and there is no significant aggregation in other cities. The AQI index of major cities in China shows a trend of aggregation of high-high areas and low-low areas.
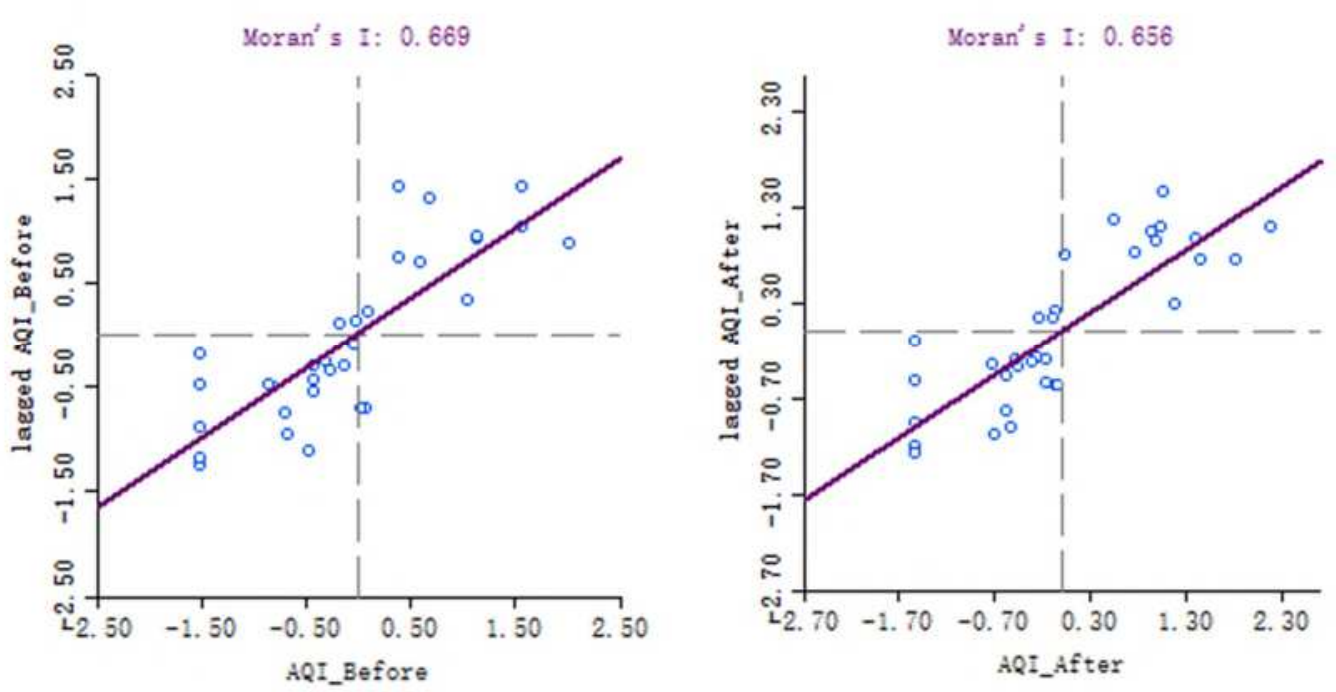

Figure 3 Global autocorrelation of AQI for China main cities before and after 18 days of "lockdown"

The AQI local autocorrelation of major cities 18 days before and after the "lockdown" is analyzed, and the AQI Lisa cluster map is drawn using ArcGIS software. It can be seen from figure 3 that 18 days before the "Lockdown," the high-high aggregation areas are mainly concentrated in northern China, including the Northeast area, BTH area, Inner Mongolia Autonomous Region, and Shanxi Province. Low-low aggregation areas are concentrated in the southern coastal areas, including Guangxi Province, Guangdong Province, and Hainan Province. After the "lockdown" of the city, Jilin Province in Northeast China, Hebei Province in BTH area separated from high-high aggregation areas, Guangdong Province in the Pearl River Delta and 
Hainan Province separated from low-low aggregation areas. China's urban air quality index AQI presents the high aggregation in the north and low aggregation in the south, and there are more aggregation areas in the north. Such aggregation characteristics show that the implementation efficiency of measures in response to the "lockdown" policy of the central government is different in each area, which might lead to the change of regional air pollution AQI index, thus affecting the change of aggregation.

AQI LISA Cluster Map: 18 Days Before AQI LISA Cluster Map: 18 Days After

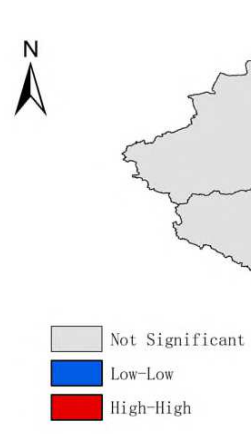

Figure 4 Local autocorrelation of AQI for China main cities before and after 18 days of "lockdown"

\subsection{Analysis of socio-economic factors}

Table 2 shows the descriptive statistical analysis of the variables. Compared with the same period in 2019, RPV, CP, CP, and IND decreased by 39.5\%, 47.08\%, $11.05 \%$, and 4.23\%, respectively during the "lockdown" in 2020. The "lockdown" has affected China's socioeconomic activities, indicating that local governments have responded to the policy and restricted residents' living and production, the air pollutants have been reduced.

Table 2 Descriptive analysis of the variables

\begin{tabular}{lllllll}
\hline Variable & Unit & Obs & Mean & Std.Dev. & Min & Max \\
\hline AQI & - & 108 & 92.8919 & 22.60645 & 49.225 & 161.75 \\
RPV & Ten thousand people & 108 & 2592.176 & 1250.354 & 475.5862 & 4359.357 \\
CA & Million square meters & 108 & 12117.67 & 1064.374 & 10886.23 & 13761.23 \\
CP & $\%$ & 108 & 145.2407 & 15.87864 & 125.9194 & 167.6786 \\
IND & Billion kwh & 108 & 10.13148 & 41.87281 & -43.10345 & 62.5 \\
\hline
\end{tabular}

Table 3 shows the results of the analysis based on equation (3) for the historical average sample data of 40 major cities in China. The overall variance test value $\mathrm{F}$ of the model passed the significance test, indicating that the fitted model is significant. As can be seen from the results, 
the coefficients of all the explanatory variables are significant at the $1 \%$ level and are positively correlated with AQI. The AQI air index decreases with the reduction of RPV, CA, CP, and IND. Among them, RPV is used to represent the impact of vehicle exhaust, which contains a large amount of black carbon in particulate matter, it is the second most important climate change factor in the world after carbon dioxide, and the exhaust has been proven to be a major driver of China's air pollution emissions. (Walsh, 2014); CA is used to reflect the level of construction dust. As a major contributor to global greenhouse gases, the construction sector accounts for $40 \%$ of the total global energy consumption and $25 \%$ of the total global CO2 emissions (Li et al., 2021; Hong et al., 2017); CP is mainly fueled by coal, and thermal power generation in China accounts for more than $70 \%$ of the total power generation. Besides, a large amount of particulate matter $\mathrm{PM}_{2.5}$ and harmful gases $\mathrm{NO}_{x}, \mathrm{SO}_{2}$ are released during the combustion process (Shon et al., 2020). The proportion of industrial added value to GDP represents the impact of factory pollution emission levels due to the fact that China's secondary industry accounts for $70 \%$ of national energy consumption, which has played an important role in the rise of urban $\mathrm{PM}_{2.5}$ (Hao and Liu, 2016). Even though lockdown, an unprecedented policy in China, has had a significant impact on human activities, these four socioeconomic factors still significantly impact AQI values, and they are the main contributors to air pollutants in China.

Table 3 Analysis results of multiple linear regressions model

\begin{tabular}{ll}
\hline Dependent variable Model & AQI \\
\hline RPV & $0.015^{* * *}$ \\
& $(0.000)$ \\
CA & $0.039^{* * *}$ \\
& $(0.001)$ \\
CP & $3.756^{* * *}$ \\
& $(0.000)$ \\
IND & $26.798^{* * *}$ \\
& $(0.000)$ \\
Constant & $-738.818^{* * *}$ \\
& $(0.002)$ \\
Obs & 108 \\
$R^{2}$ & 0.409 \\
P-value (F statistics $)$ & 0.000 \\
\hline Note: *** $\mathrm{p}^{2} .01, * * \mathrm{p}<.05, * \mathrm{p}<.1$ &
\end{tabular}


By analyzing the spatial distribution of air quality indexes, even in regions with similar economic development levels, there are significant differences in air quality indexes in regions with similar socio-economic factors due to the comprehensive influence of climate, resources, environment, and other factors. Specifically, the air quality level in the southeast coastal area, Southwest area, and Northwest area is high; Northeast area, BTH area, and Central Plains area have poor air quality, which are the high incidence areas of haze. There are significant differences in the air quality of cities with similar economic development levels in these areas. Cities Shenzhen and Guangzhou have high economic and urbanization development levels with good air quality. However, Beijing and Hangzhou's economic development and urbanization levels are similar to Shenzhen and Guangzhou, but the air pollution is serious.

Furthermore, Nanyang and Hohhot have low economic development levels, insufficient urbanization, and poor air quality. However, Kunming and Guiyang are both backward cities in economic development, and their air quality is much better than that of Nanyang and Hohhot. It can be seen that socio-economic factors such as industrial and energy structure are important factors affecting the change of urban air quality. Urbanization driven by high pollution industries will only lead to the continuous aggravation of air pollution, but cities that rely on high-tech industries to promote economic development and urbanization have fewer pollutant emissions (Peng et al., 2021; Guo et al., 2021). At the same time, urban air quality can be affected by natural factors such as resources, climate, and environment (Melamed, Schmale and von Schneidemasser, 2016; Zhang et al., 2019; MAC Kinnon, Brouwer and Samuelsen, 2018). Therefore, although humans can control most socio-economic factors when studying the methods to inhibit the deterioration of air quality, however, we should not only rely on curbing the level of economy and urbanization to achieve the purpose of air purification but also confirm the direction and focus of environmental governance in combination with various factors mentioned above.

The "lockdown" policy of the epidemic is short-lived and temporary. However, some of its policy measures are consistent with the government's conventional environmental governance plan, such as traffic control and "Odd-even License Plate" policy, construction site shutdown is similar to 
the government's mandatory watering and dust reduction on the construction site, and factory shutdown and scale factories emission reduction policies can be corresponding. Although the "lockdown" policy is stronger than the environmental governance policy, it has improved air quality. Once the COVID-19 epidemic is over, the production and life of residents will be fully restored, the air pollutants will increase, and the air quality will still be negatively affected. Therefore, appropriate environmental protection policies based on regional characteristics can better achieve the purpose of long-term improvement of environmental quality. Because of the high population density of China's big cities, the limited traffic governance policy will bring the problems of low resource utilization and rising costs. Encouraging green travel, developing public transport, promoting clean energy vehicles, green investment in new energy vehicle manufacturers, and subsidies for new energy vehicle buyers are environmental policies for sustainable development. The government should formulate environmental protection policies for factories in various regions of China in line with local economic development. Economically backward areas mainly carry out end-of-pipe treatment for factories to ensure their rapid economic growth. Industrially developed areas can appropriately improve environmental protection requirements, urge them to develop emission reduction technologies, replace energy and improve production efficiency. Northeast area, BTH area, and other areas with high industrial pollution and high energy consumption should establish a new development concept, phase out backward production capacity, promote joint atmospheric prevention and treatment, strengthen regulatory means, optimize the industrial structure, innovate in key areas of the industrial chain and achieve high-quality development. In areas where high-tech enterprises such as the Yangtze River Delta should promote the ecological development of industrial parks, develop low-carbon technologies such as alternative energy, light energy, wind energy, and ultra-high voltage, comprehensively layout green energy to connect to the power grid, and help the region realize a green and low-carbon way of production and life.

\section{Conclusion}

This paper analyzed the change trends of $\mathrm{AQI}, \mathrm{PM}_{2.5}$, and $\mathrm{PM}_{10}$ on the "lockdown" restrictions and the social driving factors of $\mathrm{AQI}$ change in 40 major cities and seven regions in China during the "lockdown" from December 29 to February 4 in the same period of the lunar calendar from 2017 
to 2021. Compared with the 36 days after the "lockdown," the three pollutant indexes' average values showed a downward trend in the 18 days before in 2020, of which $\mathrm{PM}_{10}$ decreased the most. Compared with the same period in 2018 and 2019, the three air quality indexes showed a downward trend, of which $\mathrm{PM}_{2.5}$ decreased the most in 2018 and AQI decreased the most in 2019. Among the seven regions, the three air quality indexes in the regions with developed processing and manufacturing factories and enterprises decreased significantly after the "lockdown," while the decrease in other regions was smaller. In 2020, compared with the same period in 2019, the number of days when AQI reaches good or above levels in 7 regions in China increased except in the Northeast area. Using global and local Moran I for further analysis, it was found that the regional aggregation of air pollution in major cities is obvious. The northern region of China is a high pollution aggregation area, the low pollution aggregation area is distributed in the southern coast, and the response of the northern and southern regions to the blockade policy is heterogeneous, resulting in more significant changes in the aggregation in the northern region. By analyzing the socio-economic factors affecting the change of air quality in major cities in China, it is found that road passenger volume, construction area, coal-fired power, and industrial added value significantly impact air quality, and the "lockdown" policy effect is obvious. If the central government can strictly implement the air pollution control policy, China's air quality will significantly improve.

\section{Note on preprint server}

I have not submitted my manuscript to a preprint server before submitting it to Environmental Science and Pollution Research.

\section{Ethical Approval}

Not applicable.

\section{Consent to Participate}

Not applicable.

\section{Consent to Publish}

All the authors agree to publish this paper in this journal.

\section{Authors Contributions}


This paper was written by two authors. The paper was designed and written by Xinlin Yan, who participated in data analysis, model calculation, visualization. Dr. Tao Sun participated in writing review \& editing, supervision, and project administration. The authors ranked according to their contributions.

\section{Funding}

This work has received funding from the general project of National Social Science Foundation of China: "Research on mechanism and supportive polices of environmental pollution cooperative governance in the process of regional integration development of the Yangtze River delta" (Approval number: 19BJL035).

\section{Competing Interests}

This paper was completed by two authors, and there is no conflict of interest with any unit or individual.

\section{Availability of data and materials}

Not applicable.

\section{Reference}

Ali, S., Malik, F., Anjum, M., Siddiqui, G., Anwar, M., Lam, S., Nizami, A. and Khokhar, M., 2021. Exploring the linkage between PM2.5 levels and COVID-19 spread and its implications for socio-economic circles. Environmental Research, 193, p.110421. https://doi.org/10.1016/j.envres.2020.110421

Anselin L.(1995). Local Indicators of Spatial Association-LISA[J]. Geographical Analysis, 27(2): 93115.

Chen, Y., Jin, G., Kumar, N. and Shi, G., 2013. The promise of Beijing: Evaluating the impact of the 2008 Olympic Games on air quality. Journal of Environmental Economics and Management, 66(3), pp.424-443. https://doi.org/10.1016/j.jeem.2013.06.005

Das, M., Das, A., Sarkar, R., Mandal, P., Saha, S. and Ghosh, S., 2021. Exploring short term spatiotemporal pattern of PM2.5 and PM10 and their relationship with meteorological parameters during COVID-19 in Delhi. Urban Climate, 39, p.100944. https://doi.org/10.1016/j.uclim.2021.100944

Fujii, H., Managi, S. and Kaneko, S., 2013. Decomposition analysis of air pollution abatement in China: empirical study for ten industrial sectors from 1998 to 2009. Journal of Cleaner Production, 59, pp.22-31. https://doi.org/10.1016/j.jclepro.2013.06.059

Guo, X., Shen, Y., Chen, D., Zhao, L. and Tian, X., 2021. Quantification of reduced disease burden resulting from air quality improvement by clean energy deployment in Hebei Province, China. Energy Policy, 159, p.112584. https://doi.org/10.1016/j.enpol.2021.112584 
Hao, Y. and Liu, Y., 2016. The influential factors of urban PM2.5 concentrations in China: a spatial econometric analysis. Journal of Cleaner Production, 112, pp.1443-1453. https://doi.org/10.1016/j.jclepro.2015.05.005

Hao, Y., Peng, H., Temulun, T., Liu, L., Mao, J., Lu, Z. and Chen, H., 2018. How harmful is air pollution to economic development? New evidence from PM2.5 concentrations of Chinese cities. Journal of Cleaner Production, 172, pp.743-757. https://doi.org/10.1016/j.jclepro.2017.10.195

Hong, J., Shen, G., Peng, Y., Feng, Y. and Mao, C., 2017. Reprint of: Uncertainty analysis for measuring greenhouse gas emissions in the building construction phase: a case study in China. Journal of Cleaner Production, 163, pp.S420-S432. https://doi.org/10.1016/j.jclepro.2017.05.146

Li, B., Wang, F., Yin, H. and Li, X., 2019. Mega events and urban air quality improvement: A temporary show?. Journal of Cleaner Production, 217, pp.116-126. https://doi.org/10.1016/j.jclepro.2019.01.116

Li, J. and Cao, J., 2017. An Empirical Study on the Impact of Central Heating on Air Pollution in China. China Journal of Economics, 4(04):138-150 (in Chinese)

Li, L., Li, Q., Huang, L., Wang, Q., Zhu, A., \& Xu, J. et al., 2020. Air quality changes during the COVID-19 lockdown over the Yangtze River Delta Region: An insight into the impact of human activity pattern changes on air pollution variation. Science Of The Total Environment, 732, 139282. https://doi.org/10.1016/j.scitotenv.2020.139282

Li, N., Long, X., Tie, X., Cao, J., Huang, R., Zhang, R., Feng, T., Liu, S. and Li, G., 2016. Urban dust in the Guanzhong basin of China, part II: A case study of urban dust pollution using the WRF-Dust model. Science of The Total Environment, 541, pp.1614-1624. https://doi.org/10.1016/j.scitotenv.2015.10.028

Li, W., Xie, S., Wang, Y., Huang, J. and Cheng, X., 2021. Effects of urban expansion on ecosystem health in Southwest China from a multi-perspective analysis. Journal of Cleaner Production, 294, p.126341. https://doi.org/10.1016/j.jclepro.2021.126341

Li, X., Qiao, Y., Zhu, J., Shi, L. and Wang, Y., 2017. The “APEC blue” endeavor: Causal effects of air pollution regulation on air quality in China. Journal of Cleaner Production, 168, pp.13811388. https://doi.org/10.1016/j.jclepro.2017.08.164

Luo, Y., Zhou, D., Tian, Y. and Jiang, G., 2021. Spatial and temporal characteristics of different types of pollution-intensive industries in the Beijing-Tianjin-Hebei region in China by using land use data. Journal of Cleaner Production, 329, p.129601. https://doi.org/10.1016/j.jclepro.2021.129601

Mac Kinnon, M., Brouwer, J. and Samuelsen, S., 2018. The role of natural gas and its infrastructure in mitigating greenhouse gas emissions, improving regional air quality, and renewable resource integration. Progress in Energy and Combustion Science, 64, pp.62-92. https://doi.org/10.1016/j.pecs.2017.10.002

Melamed, M., Schmale, J. and von Schneidemesser, E., 2016. Sustainable policy-key considerations for air quality and climate change. Current Opinion in Environmental Sustainability, 23, pp.85-91. https://doi.org/10.1016/j.cosust.2016.12.003 
Miao, Y., Li, J., Miao, S., Che, H., Wang, Y., Zhang, X., Zhu, R. and Liu, S., 2019. Interaction Between Planetary Boundary Layer and PM2.5 Pollution in Megacities in China: a Review. Current Pollution Reports, 5(4), pp.261-271. 10.1007/s40726-019-00124-5

Moran, P.A.P.(1950). Notes on continuous stochastic phenomena. Biometrika 37 (1/2), 17-23.

Naqvi, H., Mutreja, G., Shakeel, A. and Siddiqui, M., 2021. Spatio-temporal analysis of air quality and its relationship with major COVID-19 hotspot places in India. Remote Sensing Applications: Society and Environment, 22, p.100473. https://doi.org/10.1016/j.rsase.2021.100473

Peng, L., Liu, F., Zhou, M., Li, M., Zhang, Q. and Mauzerall, D., 2021. Alternative-energy-vehicles deployment delivers climate, air quality, and health co-benefits when coupled with decarbonizing power generation in China. One Earth, 4(8), pp.1127-1140. https://doi.org/10.1016/j.oneear.2021.07.007

Sahu, S., Mangaraj, P., Beig, G., Tyagi, B., Tikle, S. and Vinoj, V., 2021. Establishing a link between fine particulate matter (PM2.5) zones and COVID -19 over India based on anthropogenic emission sources and air quality data. Urban Climate, 38, p.100883. https://doi.org/10.1016/j.uclim.2021.100883

Shi, P., Zhang, G., Kong, F., Chen, D., Azorin-Molina, C. and Guijarro, J., 2019. Variability of winter haze over the Beijing-Tianjin-Hebei region tied to wind speed in the lower troposphere and particulate sources. Atmospheric Research, 215, pp.1-11. https://doi.org/10.1016/j.atmosres.2018.08.013

Shon, Z., Kang, M., Park, G. and Bae, M., 2020. Impact of temporary emission reduction from a large-scale coal-fired power plant on air quality. Atmospheric Environment: X, 5, p.100056. https://doi.org/10.1016/j.aeaoa.2019.100056

Sun, Y., Lei, L., Zhou, W., Chen, C., He, Y., Sun, J., Li, Z., Xu, W., Wang, Q., Ji, D., Fu, P., Wang, Z. and Worsnop, D., 2020. A chemical cocktail during the COVID-19 outbreak in Beijing, China: Insights from six-year aerosol particle composition measurements during the Chinese New Year holiday. Science of The Total Environment, 742, p.140739. https://doi.org/10.1016/j.scitotenv.2020.140739

Venter, Z.S., Aunan, K., Chowdhury, S., Lelieveld, J., 2020. COVID-19 lockdowns cause global air pollution declines. PNAS 117 (32), 18984-18990. https://doi.org/10.1073/ pnas.2006853117

Walsh, M.P. (2014). PM2.5: global progress in controlling the motor vehicle contribution. Front. Environ. Sci. Eng. 8 (1), 1-17. https://doi.org/10.1007/s11783-014-0634-4

Wei, W., Li, Z., Xie, B., Zhou, J. and Guo, Z., 2020. Spatial distance-based integrated evaluation of environmentally sensitivity for ecological management in northwest China. Ecological Indicators, 118, p.106753. https://doi.org/10.1016/j.ecolind.2020.106753

World Health Organization (WHO), 2020. WHO coronavirus disease (COVID-19) dashboard. https://covid19.who.int/. (Accessed 15 August 2021).

Xu, J., Li, J., Zhao, X., Zhang, Z., Pan, Y. and Li, Q., 2021. Effectiveness of emission control in sensitive emission regions associated with local atmospheric circulation in $\mathrm{O} 3$ pollution reduction: A case study in the Beijing-Tianjin-Hebei region. Atmospheric Environment, 269, p.118840. https://doi.org/10.1016/j.atmosenv.2021.118840 
445 Yadav, R., Korhale, N., Anand, V., Rathod, A., Bano, S., Shinde, R., Latha, R., Sahu, S., Murthy, B. 446 and Beig, G., 2020. COVID-19 lockdown and air quality of SAFAR-India metro cities. Urban Climate, 34, p.100729. https://doi.org/10.1016/j.uclim.2020.100729

Zhang, Q., Wang, Y., Zhang, W. and Xu, J., 2019. Energy and resource conservation and air pollution abatement in China's iron and steel industry. Resources, Conservation and Recycling, 147, pp.67-84. https://doi.org/10.1016/j.resconrec.2019.04.018

Zhu, S., Yang, L., Wang, W., Liu, X., Lu, M. and Shen, X., 2018. Optimal-combined model for air quality index forecasting: 5 cities in North China. Environmental Pollution, 243, pp.842-850. https://doi.org/10.1016/j.envpol.2018.09.025 